\title{
Metabolic Vulnerabilities of Prostate Cancer: Diagnostic and Therapeutic Opportunities
}

\author{
Giorgia Zadra ${ }^{1,2}$ and Massimo Loda ${ }^{1,2,3}$ \\ ${ }^{1}$ Department of Oncologic Pathology, Dana-Farber Cancer Institute, Harvard Medical School, Boston, \\ Massachusetts 02215 \\ ${ }^{2}$ Department of Pathology, Brigham and Women's Hospital, Harvard Medical School, Boston, Massachusetts \\ 02215 \\ ${ }^{3}$ The Broad Institute, Cambridge, Massachusetts 02142 \\ Correspondence: giorgia_zadra@dfci.harvard.edu; massimo_loda@dfci.harvard.edu
}

\begin{abstract}
Cancer cells hijack metabolic pathways to support bioenergetics and biosynthetic requirements for their uncontrolled growth. Thus, cancer can be considered as a metabolic disease. In this review, we discuss the main metabolic features of prostate cancer with a particular focus on the link between oncogene-directed cancer metabolic regulation, metabolism rewiring, and epigenetic regulation. The potential of using metabolic profiling as a means to predict disease behavior and to identify novel therapeutic targets and new diagnostic markers will be addressed as well as the current challenges in metabolomics analyses. Finally, diagnostic and prognostic metabolic imaging approaches, including positron emission tomography, mass spectrometry, nuclear magnetic resonance, and their translational applications, will be discussed. Here, we emphasize how targeting metabolic vulnerabilities in prostate cancer may pave the way for novel personalized diagnostic and therapeutic interventions.
\end{abstract}

$\mathrm{C}$ urrent screening methods for prostate cancer (PCa) rely on the measurement of serum prostate-specific antigen (PSA) levels and digital rectal examination, whereas the definitive diagnosis is based on prostate biopsy and potentially imaging. Unfortunately, PSA measurement has limited sensitivity and specificity and can lead to false-positive and -negative results (Nicholson et al. 2015). Moreover, because of PCa heterogeneity and multifocality, cancers can be missed on blind biopsies. In addition, even when cancer is found, areas of high grade may go undetected, posing a challenge in terms of choice of therapeutic options. Although profiling the genome and transcriptome has contributed to the identification of predictive biomarkers (Penney et al. 2011), more sensitive and specific diagnostic and prognostic biomarkers should be assessed noninvasively. Thus, the investigation of the metabolome, the repertoire of small molecule metabolites, which can be obtained in biofluids, provides a measure of the molecular pathways that are perturbed by events in the other "omes" (Goodacre et al. 2004). The development of more sophisticated bioinformatics methods to integrate metabolomics with the other "omics" have recently made this possible (Kuo et al. 2013; Alonso et al. 2015).

Editors: Michael M. Shen and Mark A. Rubin

Additional Perspectives on Prostate Cancer available at www.perspectivesinmedicine.org

Copyright (C) 2018 Cold Spring Harbor Laboratory Press; all rights reserved; doi: 10.1101/cshperspect.a030569

Cite this article as Cold Spring Harb Perspect Med 2018;8:a030569 
The study of PCa metabolism involves both the use of techniques that provide a static snapshot of the metabolome (untargeted metabolomics) or a defined set of biological/clinical relevant metabolites (targeted metabolomics). These are mostly based on mass spectrometry (MS) and nuclear magnetic resonance (NMR). Complementary metabolic flux analyses using stable isotopes provide information about reaction rates and metabolite fates. Excellent reviews have addressed the opportunities and challenges of the field (Cacciatore and Loda 2015; Zamboni et al. 2015; Wishart et al. 2016). Here, we provide an overview of the main metabolic vulnerabilities characterizing PCa initiation and progression. The link between driver oncogenes and metabolic alterations will be discussed. The use of metabolic profiling to predict disease behavior, the identification of novel metabolic biomarkers for imaging, as well as the discovery of key metabolic enzymes as potential therapeutic targets will also be addressed.

\section{MAJOR METABOLIC ALTERATIONS IN PROSTATE CANCER}

Normal prostate has a unique metabolic profile characterized by accumulation of zinc and citrate (Costello and Franklin 2000). Zinc inhibits the enzyme $\mathrm{m}$-aconitase, which is responsible for the conversion of citrate to isocitrate, causing citrate accumulation and preventing its further oxidation in the tricarboxylic acid (TCA) cycle. Thus, the production of large amounts of citrate required for the secretion into prostatic fluid is bioenergetically costly and prostate epithelial cells naturally turn to aerobic glycolysis to compensate for energy production. During transformation, zinc levels drop and $\mathrm{m}$-aconitase activity is no longer inhibited, allowing citrate to be oxidized via TCA or to be used as substrate for de novo fatty acid (FA) synthesis (Costello and Franklin 2006; Singh et al. 2006). As a result, PCa cells are more oxidative than normal ones, a feature that contrasts with the concept that tumor cells show increased aerobic glycolysis (Warburg effect). Indeed, primary PCas show minimal ${ }^{18}$ F-fluoro-2-deoxyglucose (FDG) up- take as assessed by positron emission tomography (PET) imaging.

\section{Glucose Metabolism}

Cancer cells generally display increased glycolysis for energy and biomass production (Vander Heiden et al. 2009). Although aerobic glycolysis is not a metabolic hallmark of primary $\mathrm{PCa}$ (Jadvar 2009, 2011), an increased glycolytic phenotype has been described in advanced stages of PCa. Specifically, components of the glycolytic pathway are associated with metastases formation and poor prognosis, whereas monocarboxylate transporters, which ensure the rapid efflux of lactate, represent suitable therapeutic targets (Pertega-Gomes et al. 2013). Similarly, small-cell neuroendocrine carcinoma (SCNC), an aggressive and lethal form of $\mathrm{PCa}$, displays increased glycolysis. The cell-surface marker CD44 is an important regulator of glucose metabolism in SCNC and a potential target in this PCa subtype (Li et al. 2016). In addition to glycolysis and the TCA cycle, glucose can also be directed to the pentose phosphate pathway (PPP). In fact, androgen receptor (AR) signaling increases the levels of glucose-6-phosphate dehydrogenase (G6PD), a key enzyme in PPP, and pharmacological inhibition of G6PD blocks androgen-mediated cell growth (Tsouko et al. 2014).

\section{Lipid Metabolism}

Increased de novo FA synthesis is an early hallmark of PCa tumorigenesis, but it is also associated with $\mathrm{PCa}$ progression and castrationresistant prostate cancer (CRPC) (Swinnen et al. 2000; Rossi et al. 2003; Ettinger et al. 2004; Zadra et al. 2013). Accumulation of lipid droplets (triglycerides and cholesterol esters) and phospholipids (phosphatidylcholine) has been observed especially in aggressive $\mathrm{PCa}$, using methods such as Oil-Red-O staining and Raman spectroscopy (Yue et al. 2014). Although lipid accumulation in cancer cells has long been considered an epiphenomenon that accompanies tumorigenesis, it is now well recognized that there is a functional role played by these molecules. Lipids are building blocks for mem- 
brane production, play a role in energy supply and storage, and act as mediators/modulators of intracellular signaling. Increased lipid synthesis gives an advantage to PCa cells in terms of growth rate and drug resistance, while supporting PCa survival in hostile and hypoxic microenvironments (Ackerman and Simon 2014). Whereas most normal cells rely on exogenous lipids provided with the diet, PCa cells seem to require de novo lipogenesis and overexpress lipogenic and lipid-modifying enzymes such as fatty acid synthase (FASN), acetyl-CoA carboxylase (ACC), ATP citrate lyase (ACLY), stearoyl-CoA desaturase (SCD), as well as their transcriptional regulators such as the sterol regulatory element-binding proteins (SREBPs). In particular, FASN up-regulation is an early event in the development of PCa (Swinnen et al. 2000, 2002) and its expression is further elevated in metastases and CRPC (Rossi et al. 2003; Ettinger et al. 2004; Montgomery et al. 2008). Knockdown (KD) or pharmacological treatment of FASN strongly inhibits cell proliferation and induces apoptosis (De Schrijver et al. 2003), whereas FASN overexpression in normal epithelial cells is sufficient to drive their transformation and to induce the onset of agedependent prostate intraepithelial neoplasia (PIN) (Migita et al. 2009). Taken together, these findings support an essential role of lipid metabolism in the development and progression of PCa. Alterations in FA desaturation and elongation are also associated with PCa progression. Indeed, overexpression of SCD1, the enzyme that catalyzes the production of monounsaturated FA, and the long-chain FA elongase ELOVL7 have been observed in PCa, whereas their inactivation results in the abrogation of androgen synthesis, cell proliferation, and tumor growth in vivo (Tamura et al. 2009; Fritz et al. 2010). Recently, ACSS2 (acetyl-CoA synthetase 2), the enzyme that allows the use of acetate (instead of glucose and glutamine) as the source for acetyl-CoA for FA synthesis, has been found up-regulated in metastatic PCa and associated with the ability for PCa cells to use acetate for lipid biomass production in harsh tumor microenvironments (Schug et al. 2015).
PCa cells can also take up exogenous lipids from the circulation and actively stimulate mobilization and release of stored lipids from intracellular lipid droplets or adipocytes in the tumor microenvironment to support their growth and survival (Kuemmerle et al. 2011; Zaidi et al. 2013). In this regard, monoacylglycerol lipase (MAGL), the enzyme that catalyzes the release of FAs from intracellular lipid stores is up-regulated in CRPC cells, whereas MAGL KD reduces PCa aggressiveness (Nomura et al. 2011). Similarly, lipoprotein lipase (LPL), responsible for the release of FA from triglyceride in circulating lipoprotein particles, is increased in $\mathrm{PCa}$ tissues (Kuemmerle et al. 2011). PCa cells predominantly use these released FAs as energy substrates through their oxidation (FAO) or as oncogenic signaling molecules (Louie et al. 2013). FAO is now recognized as an important player in PCa development, progression, and possibly drug resistance. This is supported by the observations that the gene encoding carnitine palmitoyltransferase $1 \mathrm{~A}(C P T 1 A)$, the ratelimiting enzyme for the transport of FA in the mitochondria for their oxidation, is amplified in $11 \%$ of metastatic tumors (Robinson et al. 2015) and in $22 \%$ of SCNC (Beltran et al. 2016). Moreover, pharmacological inhibition of CPT1 suppresses the proliferation of both androgensensitive and castration-resistant cells, reduces tumor growth in vivo, and increases the sensitization to last-generation antiandrogen drugs, such as enzalutamide (Schlaepfer et al. 2014; Schlaepfer I, unpubl.). Finally, the peroxisomal enzyme, $\alpha$-methylacyl-CoA racemase (AMACR), which converts branched chain and very long FAs in forms suitable for FAO, is commonly overexpressed in PCa (Luo et al. 2002; Rubin et al. 2002), and it is routinely used as a clinical biomarker to distinguish malignant from normal prostate tissues.

Taken together, these data suggest that a tuned balance between FA synthesis and oxidation exists in PCa cells to provide both biomass generation and the energy required to support growth and survival.

PCa is also characterized by profound alterations in cholesterol metabolism. Hypercholesterolemia is associated with increased risk of 
PCa (Bravi et al. 2006; Magura et al. 2008; Kok et al. 2011), whereas cholesterol-lowering medications such as statins appear to be beneficial in reducing PCa risk, especially for advanced disease (Platz et al. 2006, Lustman et al. 2014), although results from clinical studies have been controversial and biased (Babcook et al. 2016). Mechanistic preclinical studies have highlighted the dysregulation of cholesterol metabolism in PCa at the cellular level (Freeman and Salomon 2004; Pelton et al. 2012). Phosphatase and tensin homolog (PTEN) loss and subsequent activation of $\mathrm{PI} 3 \mathrm{~K} / \mathrm{Akt} / \mathrm{mammalian}$ target of rapamycin complex 1 (mTORC1) promote the up-regulation of SREBP-2 and lowdensity lipoprotein (LDL) receptors, resulting in cholesteryl-ester accumulation. Conversely, the pharmacological or genetic inhibition of the esterification results in apoptosis accompanied by a decrease in cellular proliferation, migration, and invasion both in vitro and in vivo (Yue et al. 2014).

The profound lipid metabolism rewiring that prostate cells undergo during transformation and disease progression offers significant therapeutic opportunities (Fig. 1).

\section{Amino Acid Metabolism}

Amino acids constitute both building blocks for protein synthesis and intermediate metabolites for biosynthetic reactions. Alterations in amino acid metabolism have been associated with both early stages of tumorigenesis as well PCa progression (Putluri et al. 2011). One of the more intensely studied amino acids in the cancer field is glutamine, the most abundant amino acid in plasma. Cancer cells use glutamine as an alternative fuel source to glucose for the TCA cycle, as a source of acetyl-CoA for FA production through reductive carboxylation (Mullen et al. 2012), and as a nitrogen donor for nucleotide synthesis to support tumor growth. Glutamine addiction is often the result of neoplastic transformation driven by oncogenes such as c-MYC (Wise and Thompson 2010), whose gene amplification/overexpression is commonly seen in PCa (The Cancer Genome Atlas Research Network 2015). Another important role for amino acids is the control of cell signaling through the nutrient sensor mTORC1. The tumor suppressor PTEN is commonly mutated or deleted in $\mathrm{PCa}$, leading to up-regulation of the PI3K-AktmTORC1 signaling pathway (Robinson et al. 2015; The Cancer Genome Atlas Research Network 2015). The amounts of intracellular amino acids, such as the essential amino acid leucine, determine the activity of mTORC1 through Rag complexes on the lysosome surface (Sancak et al. 2010; Zoncu et al. 2011). The L-type amino acid transporters such as LAT1 and LAT3 are overexpressed in PCa and their inhibition leads to decreased cell growth and mTORC1 signaling (Wang et al. 2011).

Glutamine also controls mTORC1 signaling by enhancing leucine transport (Nicklin et al. 2009). The major glutamine transporter in cancer cells is alanine-serine-cysteine transporter2 (ASCT2 or SLC1A5), which is expressed in both normal prostate and PCa (Li et al. 2003). ASCT2 expression is increased in PCa patient samples. Pharmacological or genetic inhibition of ASCT2 inhibits cell-cycle progression, growth, and metastasis in vivo (Wang et al. 2015). The metabolism of glutamine-associated amino acid proline also plays a critical role during tumorigenesis and PCa progression. The AR-dependent enzyme pyrroline-5-carboxylate reductase 1 (PYCR1), which catalyzes the NADPH-dependent conversion of pyrroline-5-carboxyate (P5C) to proline, is increased in $\mathrm{PCa}$, particularly in metastatic tumors, and reduced following androgen-deprivation therapy (ADT) (Jariwala et al. 2007). Moreover, cMYC has been shown to induce the expression of enzymes involved in proline biosynthesis (Liu et al. 2012), which promotes tumor growth by maintaining the content of pyridine nucleotides (Liu et al. 2015b).

\section{One-Carbon Metabolism}

One-carbon metabolism is comprised of the folate and the methionine cycles. In the former, tetrahydrofolate (THF) acts as a carbon carrier donor for the synthesis of purines and thymidilates, which are vital for DNA synthesis and repair. The transfer of methyl groups from 5- 


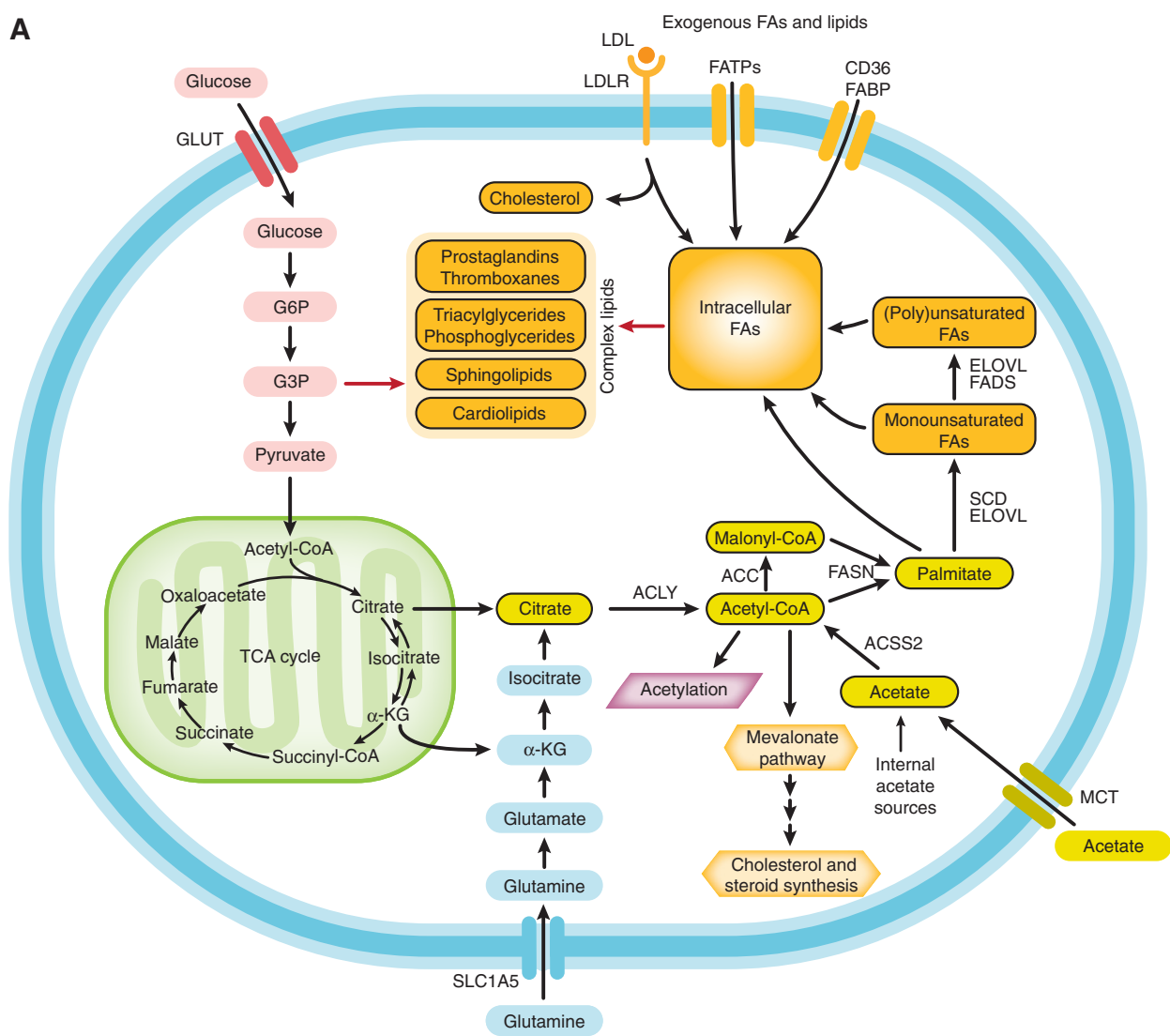

B

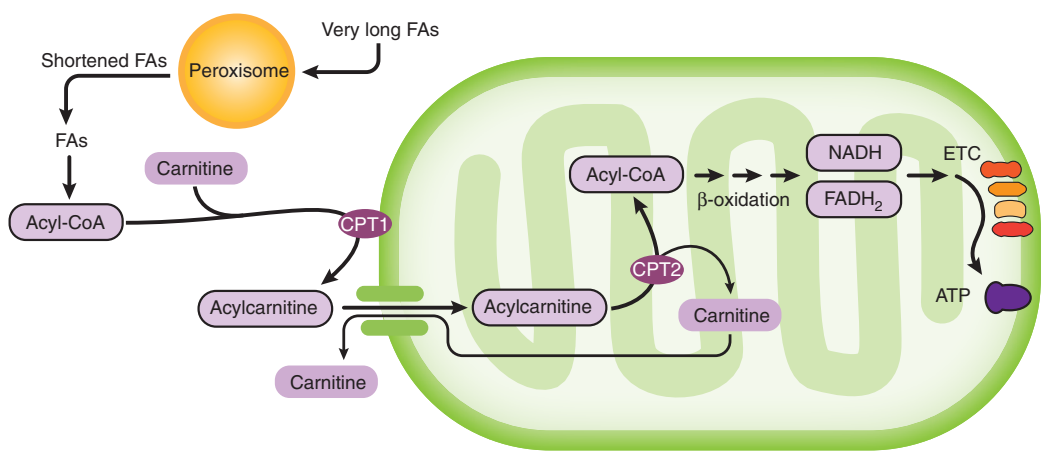

Figure 1. Prostate cells increased both the synthesis and utilization of fatty acids (FAs) during cellular transformation and prostate cancer progression. $(A)$ Simplified illustration of FA synthesis and associated pathways. Sources of carbon for de novo FA synthesis derive primarily from glucose and glutamine. In harsh environments, acetate can also be used as a carbon source. Once synthesized, de novo FAs undergo elongation and saturation modifications. FAs are also provided by diet and they can be uptaken from the circulation through transporters, binding proteins, or passive transport. Diet is the only source of essential FAs. Once in the cells, FAs are incorporated in more complex structural, storage lipids, and inflammatory mediators or $(B)$ oxidized in peroxisomes or mitochondria to produce energy. GLUT, glucose transporter; LDL, low-density lipoprotein; LDLR, low-density lipoprotein receptor; FATPs, fatty-acid transport proteins; FABP, fatty-acid-binding protein; ACLY, ATP citrate lyase; ACC, acetyl-CoA carboxylase; FASN, fatty acid synthase; ACSS2, cytoplasmic acetyl-CoA synthetase; SCD, stearoyl-CoA desaturase; ELOVL, fatty acid elongase; $\alpha$-KG, $\alpha$-ketoglutarate; G3P, glyceraldehyde-3-phosphate; G6P, glucose-6-phosphate; TCA, tricarboxylic acid; MCT, monocarboxylate transporter; CPT1, carnitine palmitoyltransferase I; CPT2, carnitine palmitoyltransferase II; NADH, reduced nicotinamide adenine dinucleotide; $\mathrm{FADH}_{2}$, reduced flavin adenine dinucleotide; ETC, electron transport chain; ATP, adenosine triphosphate. 


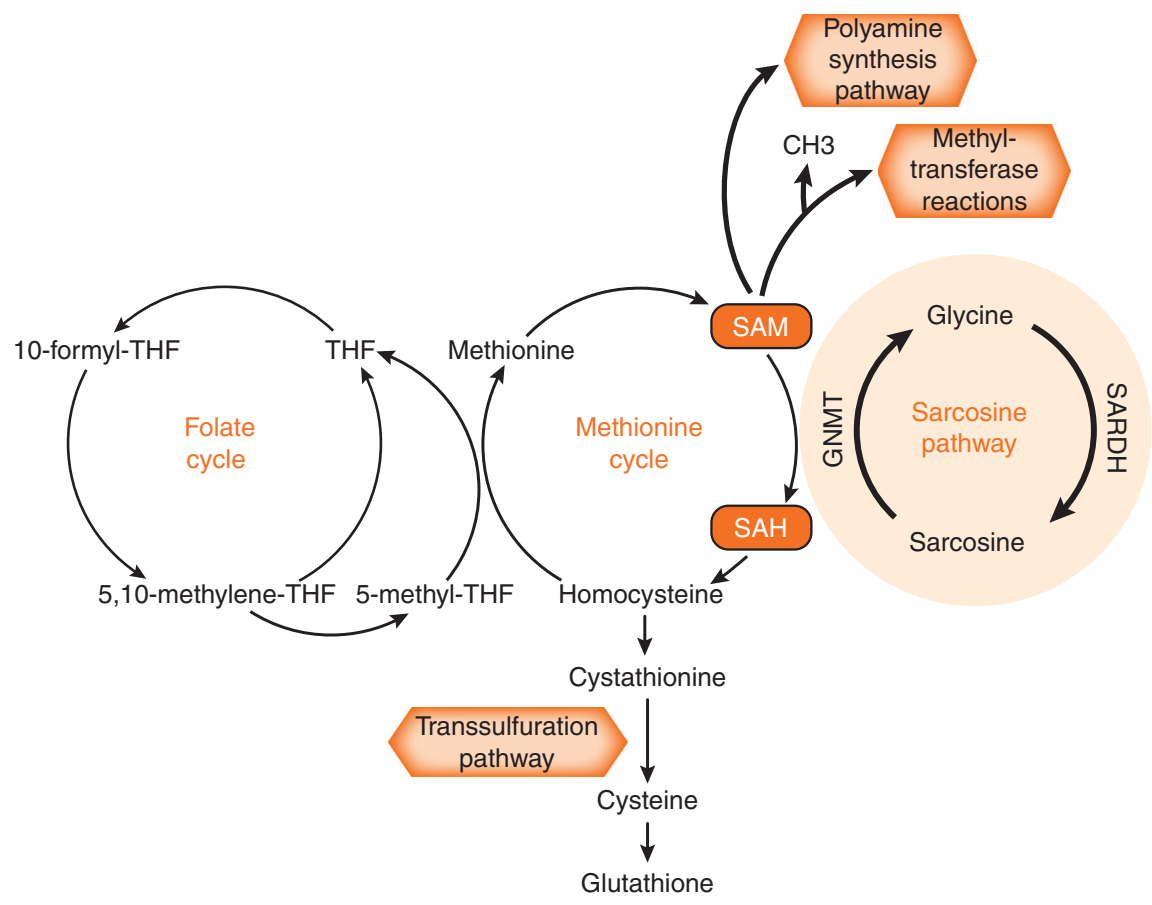

Figure 2. Scheme of one-carbon metabolism. Increased sarcosine levels are found in metastastic prostate cancers (PCas). THF, Tetrahydrofolate; SAM, S-adenosylmethionine; SAH, S-adenosylhomocysteine; GNMT, glycine $N$ methyltransferase; SARDH, sarcosine dehydrogenase.

methyl-THF to homocysteine to form methionine links the two cycles. Methionine is then converted to $S$-adenosylmethionine (SAM), the universal methyl donor for protein and DNA methyltransferase reactions. The release of the methyl group converts SAM to $S$-adenosylhomocysteine (SAH) and then back to homocysteine to close the cycle. SAM can contribute to the synthesis of polyamines, small organic cations that regulate multiple biological processes, including translation and proliferation (Williams-Ashman 1979), whereas homocysteine can be shunted to the transsulfuration pathway where it is converted into cystathionine, a precursor of the antioxidant glutathione (Fig. 2). Thus, one-carbon metabolism pathway is essential for cellular homeostasis and redox status maintenance and its disruption contributes to the pathogenesis and progression of several cancers, including PCa (Corbin and Echevarría 2016). In this regard, alteration in folate intake has been associated with PCa risk and progres- sion. However, the timing of folate supplementation for the disease progression is likely criti$\mathrm{cal}$, as studies indicate that folate may be both protective against neoplastic transformation and a promoter of growth within established lesions (Ulrich and Potter 2007).

In PCa, SAM is also used as a methyl donor by the enzyme glycine $N$-methyltransferase to form sarcosine from glycine. Markedly elevated levels of sarcosine ( $\mathrm{N}$-methylglycine) have been found in metastatic PCa tissue and modest but significant elevation in urine from the same patients. In line with this, sarcosine levels were increased in invasive PCa cell lines and the KD of glycine- $\mathrm{N}$-methyltransferase was able to attenuate PCa invasion. Conversely, the addition of exogenous sarcosine or $\mathrm{KD}$ of sarcosine dehydrogenase (SARDH), the enzyme that leads to sarcosine degradation, induced an invasive phenotype, suggesting that sarcosine is an important metabolic intermediary in the invasive process (Fig. 2). In support of this, glycine 
$N$-methyltransferase (GNMT) and SARDH were found up- and down-regulated, respectively, in PCa (Khan et al. 2013).

\section{Hexosamine Pathway}

Glycosylation is a common protein modification that affects diverse functions such as motility and cell adhesion. $O$-GlcNAcylation, the addition of $O$-linked $\beta$ - $N$-acetylglucosamine moieties to proteins by the enzyme O-GlcNAc transferase (OGT), is a nutrient sensor pathway and is commonly altered in cancers. The metabolite uridine diphosphate- $N$-acetylglucosamine (UDP-GlcNAc), which is required for protein and lipid glycosylation as well as for proper endoplasmic reticulum (ER)-Golgi trafficking and suppression of the ER stress pathway, is a product of the hexosamine biosynthesis pathway (HBP) (Altman et al. 2016). Increased expression and activity of OGT have been shown to be crucial for the survival and progression of PCa (Lynch et al. 2012). Interestingly, however, using a novel network-based integrative approach, HBP inhibition rather than its overexpression promotes CRPC. This is accomplished by either activation of the PI3K-AKT pathway in cells expressing full-length AR or by specific protein 1 (SP1)-regulated expression of carbohydrate response element-binding protein (ChREBP) in cells containing the AR splicing variant V7. The latter is known to be associated with enzalutamide treatment resistance. Strikingly, addition of UDP-GlcNAc significantly decreases CRPC proliferation and enhances enzalutamide efficacy, suggesting a potential therapeutic advantage of targeting $\mathrm{HBP}$ in CRPC (Kaushik et al. 2016).

The Influence of Diet and Systemic Metabolism on PCa Metabolome

Epidemiological data have linked metabolic diseases, including obesity and metabolic syndrome (MetS), to the risk of developing more aggressive and lethal PCa (Giovannucci et al. 2007; Cao et al. 2011). However, how systemic metabolic alterations actually affect metabolic pathways in cancer cells or whether these rewire metabolic networks to support a more aggressive phenotype remains to be explored. Several studies in preclinical models with different genetic backgrounds have shown that high-fat diet (HFD)-induced obesity (DIO) promotes PCa progression by inducing metabolic changes and promoting inflammation (Kobayashi et al. 2008; Blando et al. 2011; Liu et al. 2015a). DIO is sufficient to rescue growth in tumor cells lacking MAGL, suggesting a link between exogenous sources of FAs and tumorigenesis (Nomura et al. 2010). Recently, a comparative metabolomics analysis performed in MYC-transformed and wild-type prostates from lean and obese mice fed with DIO uncovered a robust metabolic rewiring induced by DIO in the MYC-transformed prostate but not in the normal prostate associated with PCa progression (DP Labbé and G Zadra, unpubl.). It has been also reported that periprostatic adipocytes, which accumulate in obese patients, signal to PCa cells to enhance motility via secretion of cytokines (Laurent et al. 2016). Unfortunately, metabolic alterations in this setting have not been assessed. These findings begin to uncover the mechanisms by which altered systemic metabolism affects the metabolic pathways and biologic behavior in PCa cells. It is tempting to suggest that dietary interventions can be implemented therapeutically to inhibit tumor progression.

\section{METABOLIC REWIRING AS AN INTEGRATOR OF GENETIC AND EPIGENETIC ALTERATIONS IN PCa}

Substantial evidence suggests that oncogenes directly regulate critical metabolic enzymes and metabolic signaling pathways. The oncogenes c-MYC, KRAS, and AKT have been identified as key players in rewiring cancer metabolism and several comprehensive reviews have addressed this topic (Cairns et al. 2011; Dang 2012; Iurlaro et al. 2014; Kimmelman 2015; Nagarajan et al. 2016).

The overexpression of $\mathrm{c}-\mathrm{MYC}$ and the aberrant activation of the PTEN/PI3K/AKT/ mTORC1 pathway play a role in both $\mathrm{PCa}$ initiation and progression (Jenkins et al. 1997; Gurel et al. 2008; Koh et al. 2010; Robinson 


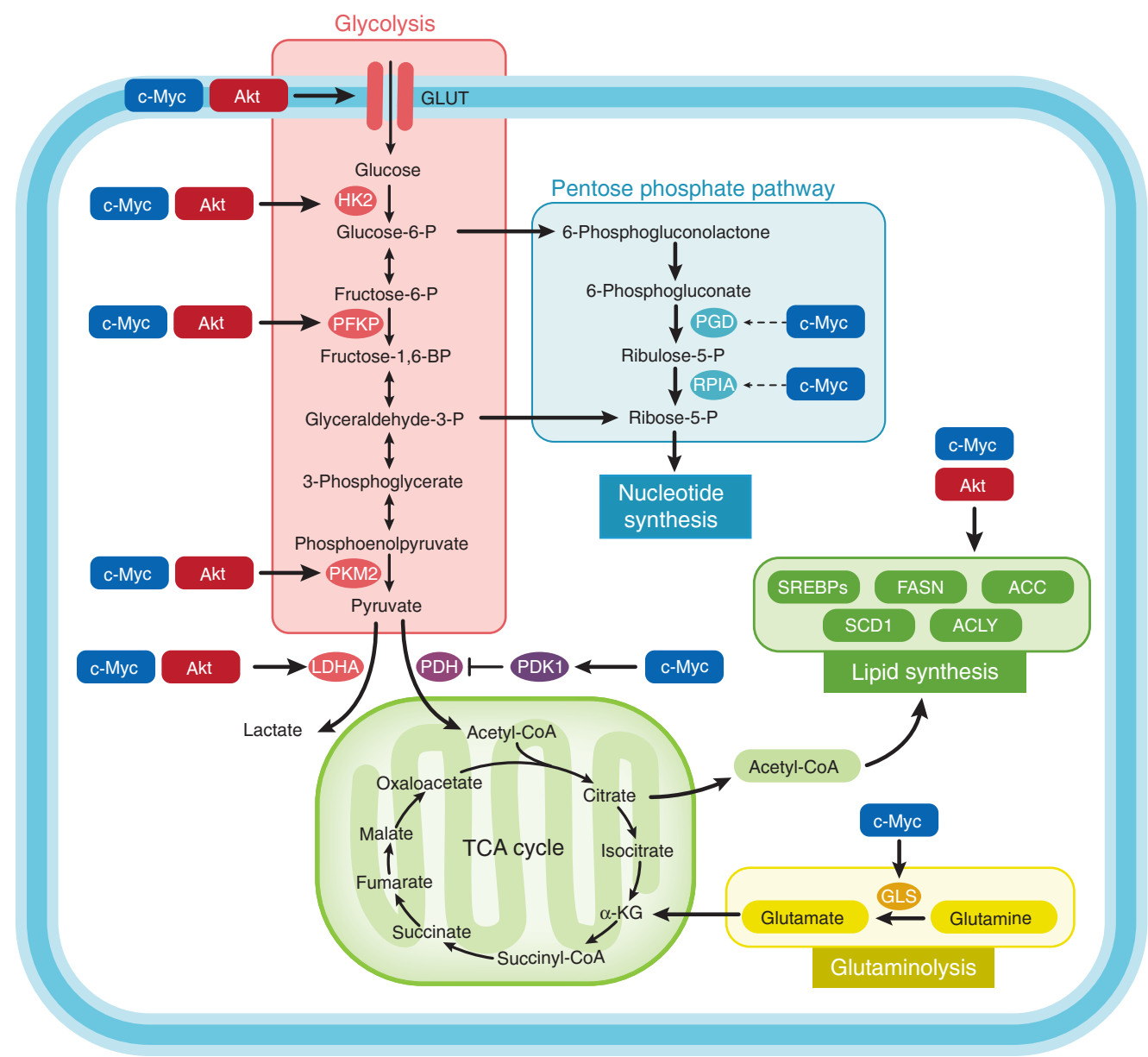

Figure 3. Oncogenes regulate tumor metabolism. This simplified scheme shows that oncogenes c-MYC and AKT mediate the regulation of metabolic enzymes/transporters. HK2, Hexokinase 2; PFKP, phosphofructokinase; PKM2, pyruvate kinase; LDHA, lactate dehydrogenase; $\mathrm{PDH}$, pyruvate dehydrogenase; PDK1, pyruvate dehydrogenase kinase 1; SREBPs, sterol regulatory element-binding proteins; PGD, phosphogluconate dehydrogenase; RPIA, ribose 5-phosphate isomerase A; GLS, glutaminase.

et al. 2015; The Cancer Genome Atlas Research Network 2015; Wise et al. 2017). Enhanced PI3K/Akt signaling promotes transformation through several mechanisms, including increased nutrient uptake (e.g., AKT-induced overexpression of the glucose transporter 1 [GLUT1] and the amino acid transporters at the cell membrane), increased expression of enzymes and transcription factors involved in glycolysis and de novo lipogenesis, and enhanced protein translation through $\mathrm{mTORC} 1$ activation (Fig. 3) (Edinger and Thompson 2002; Wullschleger et al. 2006). c-MYC induces a profound metabolic rewiring cell via a transcriptional/ posttranscriptional reprogramming of central carbon (glucose and glutamine) and one-carbon metabolism. Indeed, c-MYC increases the expression/activity of enzymes and transporters involved in glutaminolysis (e.g., ASCT2, glutaminase [GLS]), glycolysis (e.g., GLUT1, hexokinase $[\mathrm{HK}]$, phosphofructokinase 3 [PFKP], pyruvate kinase $\mathrm{M}[\mathrm{PKM}]$, lactate dehydrogenase A [LDHA]), lipid synthesis (e.g., ACC, FASN, SCD1), as well as nucleotides, amino acid synthesis, mitochondrial oxidation, and ribosome biogenesis (Fig. 3). Because of space 
constraints, we refer to the outstanding reviews from Chi Dang's group for a detailed description of MYC-driven metabolic alterations (Dang 2013; Hsieh et al. 2015; Stine et al. 2015; Altman et al. 2016). Our group used an integrated metabolomics approach to show the association of Akt 1 activation with aerobic glycolysis, and of c-MYC overexpression with dysregulation of lipid metabolism, confirming that PCas show specific metabolic reprogramming that reflect their molecular phenotypes (Priolo et al. 2014). These findings suggest the potential use of drugs targeting lipogenesis in PCa characterized by MYC amplification/overexpression, as well as the use of ${ }^{11} \mathrm{C}$-acetate-PET to image these tumors and their response to metabolic targeting (Priolo and Loda 2015). Interestingly, specific metabolites such as arachidonic, docosahexaenoic, oleic acid, and sarcosine were associated with MYC overexpression, suggesting that it may be possible to molecularly stratify PCas based on a noninvasive serum metabolic profile, with implications for the development of diagnostics and targeted therapeutics.

Whereas the interplay between signal transduction and metabolic pathways is well established, the existence of important bidirectional regulatory mechanisms between metabolic alterations and the epigenome, specifically pertaining to methylation and acetylation of histones, is beginning to be explored. Indeed, most chromatin-modifying enzymes require substrates or cofactors that are intermediates of cell metabolism. Such metabolites, and often the enzymes that produce them, can transfer into the nucleus, directly linking metabolism to nuclear transcription. We refer to the excellent recent review of Kinnaird et al. (2016) for a full description of the cross talk between metabolism and epigenetics in cancer development. As described in the previous section, alterations in heat shock protein (HSP) and in one-carbon metabolism are associated with both PCa development and progression. Both of these metabolic pathways can affect the PCa epigenome. $O$-GlcNAcylation has been associated with increased monoubiquitination of $\mathrm{H} 2 \mathrm{~B}$, resulting in active transcription and regulation of DNA demethylases (TET) activity (Ma and Vosseller
2014). As for one-carbon metabolism, the SAM/ SAH ratio is known to affect the activity of DNA and histone methyltransferases (DNMTs, histone methyltransferases [HMTs]) (Mentch and Locasale 2016). We already mentioned that in metastatic $\mathrm{PCa}$, sarcosine production catalyzed by GNMT is increased. This results in higher SAH levels, possibly inhibiting DNMT and HMT. Indeed, global DNA hypomethylation has been correlated with a high Gleason score and metastatic PCa (Brothman et al. 2005; Yegnasubramanian et al. 2008). Because the substrates or cofactors for epigenetic marks can be obtained from the diet, the impact of diet on PCa development can be, at least in part, ascribed to epigenomic remodeling (Labbé et al. 2015). A better understanding of the link between metabolism and epigenetics in PCa may unravel novel molecular targets for therapeutic intervention.

\section{EXPLOITING METABOLIC VULNERABILITIES AS A THERAPEUTIC APPROACH}

Efforts have been directed at exploiting PCa metabolic vulnerabilities for the development of new therapeutic approaches. As expected, most of them have been focused on developing small molecules targeting de novo lipogenesis and FAO with improved specificity, solubility, pharmacokinetics, and reduced systemic side effects. These have in fact hampered thus far the use of these drugs into the clinic (Zadra et al. 2013).

Inhibitors targeting FASN, ACC, ACLY, and SCD1 have been successfully tested in preclinical models, and a phase I clinical trial with the FASN inhibitor TV-2640 is currently ongoing (clinicaltrials.gov) (Zadra et al. 2013, Jones and Infante 2015; E Dean, unpubl.). Moreover, preclinical data showed that statins inhibit cell proliferation, induce apoptosis, and decrease cell migration/invasion in $\mathrm{PCa}$ cells in vitro and in preclinical models (Kochuparambil et al. 2011; Miyazawa et al. 2017). Although the use of statins in PCa prevention remains controversial, several clinical trials are currently evaluating statins as neoadjuvant or adjuvant agents (clinicaltrials.gov). 
Indirect inhibitors of de novo FA synthesis and cholesterogenesis, including direct/indirect activators of the metabolic sensor $5^{\prime}$ AMP-activated protein kinase (AMPK) have also shown promising results in preclinical models of $\mathrm{PCa}$ metformin, a well-known indirect activator of $\mathrm{AMPK}$, reduces the risk of developing $\mathrm{PCa}$ in humans (reviewed in Zadra et al. 2015). However, AMPK seems to play opposing roles, depending on nutrient availability, tumor microenvironment, and genetic background, highlighting the need for a careful evaluation before AMPK activators are considered for therapeutic intervention (Zadra et al. 2015; Khan and Frigo 2017). FAO inhibitors such as trimetazidine and ranolazine are currently safely used in the clinic for heart disease and their use in PCa should be considered (Carracedo et al. 2013). A detailed description of the most promising drugs targeting lipid metabolism is available (BeloribiDjefaflia et al. 2016; Röhrig and Schulze 2016).

Many different compounds targeting glutamine transport, its conversion to glutamate, and to $\alpha$-ketoglutarate, have been examined in different cancer cell models, including $\mathrm{PCa}$, with promising results (Chen and Cui 2015; Altman 2016). Although most of these are still in the preclinical "tool compound" stage or have been limited by toxicity, allosteric inhibitors of GLS have shown promise in preclinical models of cancer, and one highly potent compound in this class, CB-839, has moved on to clinical trials. A trial is currently recruiting patients to test CB-839 in MYC-amplified/mutated solid tumors, including PCa (clinicaltrials.gov).

\section{APPLYING METABOLOMICS FOR PCa BIOMARKERS DISCOVERY}

A comprehensive review by Kelly and coworkers was published in 2016 to summarize the current studies in which metabolic profiling was used for PCa biomarkers discovery (Kelly et al. 2016). Thirty-three human case-control studies of PCa exploring disease prediction, diagnosis, progression, or treatment response were identified between 2002 and 2016, using prostate tissue, blood, urine, and prostatic secretions. The studies were attempting to identify predictive biomarkers before diagnosis to distinguish malignant from benign, to identify biomarkers of tumor aggressiveness, to investigate the effect of therapy, and to consider multiple outcomes. The majority of these studies performed metabolic profiling using MS, whereas the rest used NMR. Seventeen of them undertook an untargeted approach, and only seven were quantitative or semiquantitative. Moreover, the number of metabolites and the data reported varied among the different studies. Despite all of these limitations, the results of all but one study showed the ability of metabolite profiling to distinguish cancer from benign tumors by degree of aggressiveness, cases that recurred from those that responded well to therapy. In the subset of studies in which biomarker discriminatory ability was quantified, high areas under the receiver operating characteristic (ROC) curve (AUC) were reported. The most promising diagnostic biomarkers include sarcosine, choline, phosphocholines, phosphorylcholines, carnitines, citrate, amino acids, arachidonoyl amine, and lysophospholipids. In terms of biomarkers of tumor aggressiveness, the most promising metabolites include dihyroxybutanoicacid, xylonic acid, pyrimdine, xylopyranose, ribofuranoside, citrate, glutamate, sphingomyelin, amino acids, 5,6-dihydrouracil, glycerol, methylpalmitate, and choline phosphate. Those that show positive results in terms of predicting disease recurrence include phosphorylcholine, myoinositol, spermine, glutamate, cysteine, choline, creatine, and glutamine. In all tissuebased diagnostic studies, a good correlation between metabolic findings and histopathology in discriminating PCa from normal tissue was found. Moreover, McDunn and colleagues (2013) reported that the inclusion of a metabolic profile provided increased prediction of recurrence compared with clinical indices alone.

Despite the positive results, a number of important methodological and confounding/bias issues remain to be addressed. In addition, validation studies must be performed before metabolomics-based biomarkers can be translated in the clinic. Nevertheless, metabolites might eventually outperform the current gold standards in diagnosis, prognosis, and recurrence prediction. 
Recently, our group showed the feasibility and accuracy of performing metabolite profiling in formalin-fixed and paraffin embedded (FFPE) tissues (Cacciatore et al. 2017). These results pave the way for metabolomics-based biomarker discovery/validation using retrospective and clinically annotated FFPE sample collections.

\section{METABOLIC IMAGING OF PROSTATE CANCER}

Metabolic alterations have been exploited for imaging purposes to improve noninvasive diagnosis, staging, and therapeutic monitoring.

The most common metabolic imaging methods are magnetic resonance spectroscopy imaging (MRSI) and PET. More recently, multiparametric magnetic resonance imaging (mpMRI), hyperpolarized MRSI, PET/computerized tomography (CT) and PET/MRI have been used.

MRSI is a noninvasive technique that spares the use of nonionizing radiation and allows the mapping of multiple metabolites with a spatial resolution $<0.5 \mathrm{~cm}^{3}$. Metabolite detection is based on their resonance frequency (Verma et al. 2010). As described above, PCa is associated with change in citrate levels and its oxidation rate. Specifically, lower levels of citrate and polyamines and higher levels of choline and creatine are seen in PCa in comparison to benign tissue. This difference (ratio choline + creatine/citrate) is known to increase with tumor aggressiveness (Costello and Franklin 2000) and it can be specifically detected by MRSI (Kurhanewicz et al. 1996, 2008). MRSI is usually combined with MRI to visualize the zonal anatomy of the prostate and better delineate tumor location, volume, and stage. In a systematic review and meta-analysis of the use of combined MRI and MRSI in PCa, sensitivity for the evaluation of the primary tumor was $68 \%$ (95\% CI, $56 \%-78 \%)$ with a specificity of $85 \%$ (95\% CI, 78\%-90\%) (Umbehr et al. 2009). Several studies have shown that MRSI can improve the cancer-detection rate, particularly in intermediate- and high-risk patients (Javali et al. 2014). It is useful in guiding the decision to preserve or resect the neurovascular bundles during radical prostatectomy (Hricak et al.
2005), detecting tumors in patients with previously negative biopsy and persistently abnormal PSA (Prando et al. 2005), and in assessing response to radiation and/or ADT (Pickett et al. 2004; Carroll et al. 2006). The main drawbacks of MRSI remain the detection of small lesions and the technical challenge in spectra interpretation, especially for transitional and central zones of the prostate (Zakian et al. 2003), where the normal tissues do not accumulate substantial citrate and the discriminatory ratio (choline + creatine/citrate) is more difficult to assess.

Whereas MRSI detects static concentrations of endogenous molecules, PET detects differential tracer uptake by the tumor based on its altered metabolic addiction. PET is usually associated with CT scan to provide both metabolic and morphological information. Based on exposure to ionizing radiation, PET is characterized by a high sensitivity but low spatial resolution. The most commonly used tracer for PET imaging is FDG. However, as mentioned above, primary PCa does not usually show a marked increased glycolytic phenotype, thus FDG-PET generally has a limited utility in the diagnosis, staging, and restaging of PCa (Salminen et al. 2002; Jadvar et al. 2012). However, different studies suggest that FDG-PET may be useful in the assessment of treatment response and prognosis for metastatic PCas (Oyama et al. 2001; Jadvar 2011).

The limited utility of FDG-PET has prompted the development of different tracers of lipid metabolism. In this regard, ${ }^{11} \mathrm{C}$-acetate (a precursor of FA synthesis) and ${ }^{11} \mathrm{C}$ - and ${ }^{18} \mathrm{~F}$-fluorocholine (precursor in phospholipid biosynthesis) are the most used tracers in PCa (Czernin et al. 2009). Increased ${ }^{11} \mathrm{C}$-acetate uptake is mainly related to an enhanced lipid synthesis in PCa. ${ }^{11} \mathrm{C}$-acetate appears to be useful and superior to FDG in the detection of tumor recurrence and metastatic disease (Fig. 4) (Kotzerke et al. 2002, Oyama et al. 2003; Sandblom et al. 2006; Schumacher et al. 2015). The major limitation of ${ }^{11} \mathrm{C}$ tracers is the availability of a cyclotron on site and the very rapid half-life of this tracer $(20 \mathrm{~min})$. As a result, ${ }^{18} \mathrm{~F}$-labeled formulations of acetate with prolonged half-life have been used, although clinical experience 

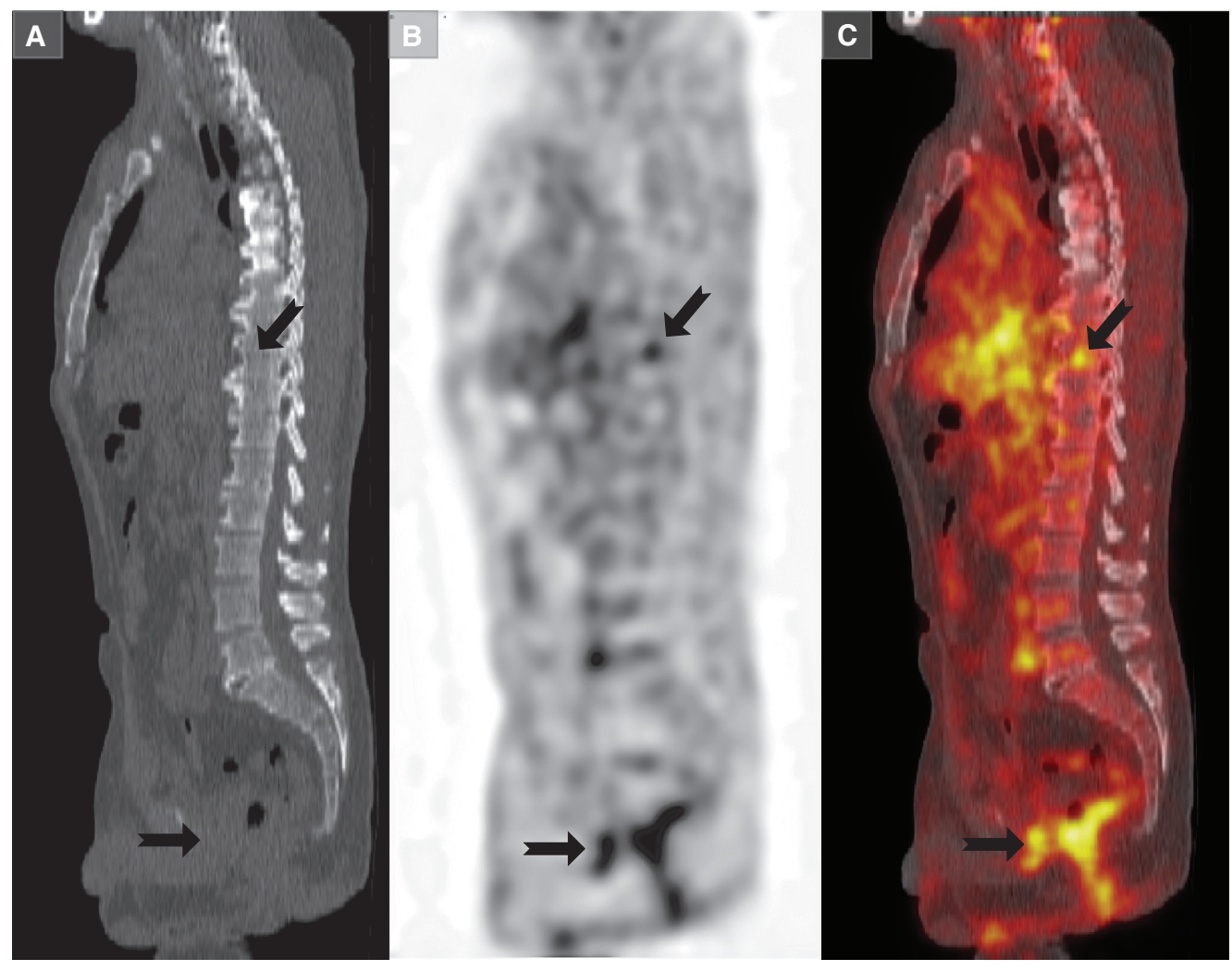

Figure 4. Representative image of ${ }^{11} \mathrm{C}$-acetate positron emission tomography (PET)/computerized tomography (CT). ${ }^{11} \mathrm{C}$-acetate PET/CT was performed in a patient with increasing prostate-specific antigen (PSA) levels (biochemical recurrence) after prostatectomy. (A) Sagittal midline CT image, $(B){ }^{11} \mathrm{C}$-acetate image from same location as in $A$, and $(C)$ fused image. Increased ${ }^{11} \mathrm{C}$-acetate uptake (depicted with black arrows) indicates sites of otherwise inapparent metastases. (This image was kindly provided by Prof. Umar Mahmood and Dr. Pedram Heidari, Massachusetts General Hospital, Boston, MA.)

with this tracer remains limited (Matthies et al. 2004).

The use of choline as a radiotracer is based on the up-regulation of choline kinase, which leads to the incorporation and trapping of choline in the form of phosphatidylcholine in cell membranes. Whether ${ }^{18} \mathrm{~F}$-choline or ${ }^{11} \mathrm{C}$-choline PET/CT are able to discriminate PCa tissue from benign entities within the prostate remains controversial; however, promising results have been shown for the detection of PCa recurrence (Richter et al. 2010), even when the PSA value is lower than $1 \mathrm{ng} / \mathrm{mL}$ (Giovacchini et al. 2010). In terms of bone metastasis detection, ${ }^{11} \mathrm{C}$-choline is complementary to bone scintigraphy, with the former offering higher specificity and the latter providing higher sensitivity (Picchio et al. 2012).

${ }^{11} \mathrm{C}$-choline PET/CT is successfully used in clinical staging of advanced disease (Tuncel et al. 2008) and in evaluating therapy response (Krause et al. 2010).

PET tracers based on amino acid metabolism have also been evaluated, including ${ }^{11} \mathrm{C}$ methionine, anti-1-amino- $3-{ }^{18} \mathrm{~F}$-fluorocyclobuate-1-carboxylic (anti- ${ }^{18} \mathrm{~F}-\mathrm{FACBC}$ ), and 4 ${ }^{18} \mathrm{~F}-(2 \mathrm{~S}, 4 \mathrm{R})$-fluoroglutamine $\left({ }^{18} \mathrm{~F}\right.$-fluoro-Gln). Relatively scant data have been published on ${ }^{11} \mathrm{C}$-methionine imaging in $\mathrm{PCa}$, but these reported higher sensitivity of ${ }^{11} \mathrm{C}$-methionine when compared with FDG-PET in both primary detection and recurrence (Nuñez et al. 2002; Tóth et al. 2005). 
Anti- ${ }^{18} \mathrm{~F}-\mathrm{FACBC}$ is a synthetic L-leucine analog that accumulates in PCa with relatively limited renal excretion (Oka et al. 2007). Anti- ${ }^{18} \mathrm{~F}-$ FACBC-PET has been used to detect recurrent disease and in detecting occult extraprostatic sites of disease in men with biochemical failure with good sensitivity and specificity (Schuster et al. 2011). PET imaging using the glutamine analog ${ }^{18} \mathrm{~F}$-fluoro-Gln has shown promising results in glioma patients (Venneti et al. 2015) and should thus be considered for PCa imaging.

One of the latest molecular imaging modalities developed is hyperpolarized ${ }^{13} \mathrm{C}$-MRSI. This technique combines the advantages of MRSI with an enormous gain in sensitivity owing to molecule hyperpolarization as well as the assessment of metabolic fluxes rather than a static snapshot (Golman and Pettersson 2006; Kurhanewicz and Vigneron 2008; Kurhanewicz et al. 2011). Technically, data must be collected as rapidly as possible because the enhancement is lost with the spin-lattice relaxation of the molecule. The most common approach used so far is MRSI with hyperpolarized ${ }^{13} \mathrm{C}$ pyruvate. ${ }^{13} \mathrm{C}$ pyruvate MRSI has shown increased sensitivity than MRI in tumor detection PCa (Albers et al. 2008) and has proven to be safe and feasible in humans. When the distribution of $1-{ }^{13} \mathrm{C}$ pyruvate and its metabolic products (lactate, alanine, and bicarbonate) is evaluated in a time range of seconds, elevated $1-{ }^{13} \mathrm{C}$ lactate $/ 1-{ }^{13} \mathrm{C}$ pyruvate ratios are found in regions of biopsy-proven cancer (Nelson et al. 2013). In addition to its use as a diagnostic tool, refinements in the approach will soon allow hyperpolarized MRSI to aid in risk stratification of organ-confined malignancy at the time of diagnosis and to serve as a powerful tool to monitor disease in patients managed on an active surveillance protocol.

\section{CONCLUDING REMARKS}

Metabolic reprogramming is a central feature of PCa development and progression. Tumor-specific metabolic vulnerabilities can be exploited to stratify patient's risk and identify new druggable targets. Targeting single genes or pathways rarely results in prolonged clinical utility. However, cotargeting central metabolic nodes that support these genetic events or activated pathways may result in cancer-specific, increased therapeutic efficacy. It is therefore likely that drugs targeting PCa metabolism will need to be combined with current standard therapies, including ADT, chemotherapy, and targeted therapy approaches. Preclinical studies conducted in the past few years have provided evidence in support of this notion.

Metabolomics and fluxome analyses are still evolving but both have already uncovered novel biochemical mechanisms underpinning PCa development and progression and provided unique metabolic liabilities associated with defined genetic alterations that can be exploited therapeutically. Given the relatively low cost of metabolic profiling compared with the other "omics" and the parallel advances being made in metabolic imaging, their combined use holds significant promise in the detection of clinically significant disease and in monitoring $\mathrm{PCa}$ progression, in both the active surveillance and posttreatment settings. Moreover, metabolomics represents a remarkable tool to explore metabolic networks influenced by genetic alterations and their interaction with the microenvironment as well as systemic alterations. The ability to perform metabolomics in FFPE tissues using large and well-annotated retrospective patient cohorts and the continuous development of new statistical and bioinformatics integrative approaches have set the stage for new opportunities in the diagnostic, prognostic, and therapeutic areas of $\mathrm{PCa}$.

\section{ACKNOWLEDGMENTS}

We thank Prof. Umar Mahmood and Dr. Pedram Heidari for kindly providing us the image of ${ }^{11} \mathrm{C}$-acetate-PET and Jane Hayward for the support in figure preparation. The authors apologize to those whose publications related to the discussed issues could not be cited owing to space limitations. G.Z. is a recipient of the Idea Development Award from the U.S. Department of Defense (DoD; PC150263) and of the Claudia Adams Barr Award from Dana-Farber Cancer Institute. This work is also supported by grants from the National Institutes of Health 
(R01CA187918), the DoD (PC130716), and the Prostate Cancer Specialized Programs of Research Excellence (P50 CA90381).

\section{REFERENCES}

Ackerman D, Simon MC. 2014. Hypoxia, lipids, and cancer: Surviving the harsh tumor microenvironment. Trends Cell Biol 24: 472-478.

Albers MJ, Bok R, Chen AP, Cunningham CH, Zierhut ML, Zhang VY, Kohler SJ, Tropp J, Hurd RE, Yen YF, et al. 2008. Hyperpolarized ${ }^{13} \mathrm{C}$ lactate, pyruvate, and alanine: Noninvasive biomarkers for prostate cancer detection and grading. Cancer Res 68: 8607-8615.

Alonso A, Marsal S, Julia A. 2015. Analytical methods in untargeted metabolomics: State of the art in 2015. Front Bioeng Biotechnol 3: 23.

Altman BJ, Stine ZE, Dang CV. 2016. From Krebs to clinic: Glutamine metabolism to cancer therapy. Nat Rev Cancer 16: 619-634.

Babcook MA, Joshi A, Montellano JA, Shankar E, Gupta S. 2016. Statin use in prostate cancer: An update. Nutr Metab Insights 9: 43-50

Beloribi-Djefaflia S, Vasseur S, Guillaumond F. 2016. Lipid metabolic reprogramming in cancer cells. Oncogenesis 5: e189.

Beltran H, Prandi D, Mosquera JM, Benelli M, Puca L, Cyrta J, Marotz C, Giannopoulou E, Chakravarthi BV, Varambally S, et al. 2016. Divergent clonal evolution of castration-resistant neuroendocrine prostate cancer. Nat Med 22: 298-305.

Blando J, Moore T, Hursting S, Jiang G, Saha A, Beltran L, Shen J, Repass J, Strom S, DiGiovanni J. 2011. Dietary energy balance modulates prostate cancer progression in Hi-Myc mice. Cancer Prev Res (Phila) 4: 2002-2014.

Bravi F, Bosetti C, Dal Maso L, Talamini R, Montella M, Negri E, Ramazzotti V, Franceschi S, La Vecchia C. 2006. Macronutrients, fatty acids, cholesterol, and risk of benign prostatic hyperplasia. Urology 67: 12051211.

Brothman AR, Swanson G, Maxwell TM, Cui J, Murphy KJ, Herrick J, Speights VO, Isaac J, Rohr LR. 2005. Global hypomethylation is common in prostate cancer cells: A quantitative predictor for clinical outcome? Cancer Genet Cytogenet 156: 31-36.

Cacciatore S, Loda M. 2015. Innovation in metabolomics to improve personalized healthcare. Ann NY Acad Sci 1346: 57-62.

Cacciatore S, Zadra G, Bango C, Penney KL, Tyekucheva S, Yanes O, Loda M. 2017. Metabolic profiling in formalinfixed and paraffin-embedded prostate cancer tissues. $\mathrm{Mol}$ Cancer Res 15: 439-447.

Cairns RA, Harris IS, Mak TW. 2011. Regulation of cancer cell metabolism. Nat Rev Cancer 11: 85-95.

Cao Y, Ma J. 2011. Body mass index, prostate cancer-specific mortality, and biochemical recurrence: A systematic review and meta-analysis. Cancer Prev Res (Phila) 4: 486-501.
Carracedo A, Cantley LC, Pandolfi PP. 2013. Cancer metabolism: Fatty acid oxidation in the limelight. Nat Rev Cancer 13: 227-232.

Carroll PR, Coakley FV, Kurhanewicz J. 2006. Magnetic resonance imaging and spectroscopy of prostate cancer. Rev Urol 8: S4-S10.

Chen L, Cui H. 2015. Targeting glutamine induces apoptosis: A cancer therapy approach. Int J Mol Sci 16: 2283022855.

Corbin JM, Ruiz-Echevarria MJ. 2016. One-carbon metabolism in prostate cancer: The role of androgen signaling. Int J Mol Sci doi: 10.3390/ijms17081208.

Costello LC, Franklin RB. 2000. The intermediary metabolism of the prostate: A key to understanding the pathogenesis and progression of prostate malignancy. Oncology 59: $269-282$.

Costello LC, Franklin RB. 2006. The clinical relevance of the metabolism of prostate cancer; zinc and tumor suppression: Connecting the dots. Mol Cancer 5: 17.

Czernin J, Benz MR, Allen-Auerbach MS. 2009. PET imaging of prostate cancer using C-acetate. PET Clin 4: 163172.

Dang CV. 2012. Links between metabolism and cancer. Genes Dev 26: 877-890.

Dang CV. 2013. MYC, metabolism, cell growth, and tumorigenesis. Cold Spring Harb Perspect Med 3: a014217.

De Schrijver E, Brusselmans K, Heyns W, Verhoeven G, Swinnen JV. 2003. RNA interference-mediated silencing of the fatty acid synthase gene attenuates growth and induces morphological changes and apoptosis of $\mathrm{LNCaP}$ prostate cancer cells. Cancer Res 63: 3799-3804.

Edinger AL, Thompson CB. 2002. Akt maintains cell size and survival by increasing mTOR-dependent nutrient uptake. Mol Biol Cell 13: 2276-2288.

Ettinger SL, Sobel R, Whitmore TG, Akbari M, Bradley DR, Gleave ME, Nelson CC. 2004. Dysregulation of sterol response element-binding proteins and downstream effectors in prostate cancer during progression to androgen independence. Cancer Res 64: 2212-2221.

Freeman MR, Solomon KR. 2004. Cholesterol and prostate cancer. J Cell Biochem 91: 54-69.

Fritz V, Benfodda Z, Rodier G, Henriquet C, Iborra F, Avances $\mathrm{C}$, Allory Y, de la Taille A, Culine S, Blancou H, et al. 2010. Abrogation of de novo lipogenesis by stearoyl-CoA desaturase 1 inhibition interferes with oncogenic signaling and blocks prostate cancer progression in mice. $\mathrm{Mol}$ Cancer Therapeut 9: 1740-1754.

Giovacchini G, Picchio M, Scattoni V, Garcia Parra R, Briganti A, Gianolli L, Montorsi F, Messa C. 2010. PSA doubling time for prediction of $\left[{ }^{11} \mathrm{C}\right]$ choline PET/CT findings in prostate cancer patients with biochemical failure after radical prostatectomy. Eur J Nucl Med Mol Imaging 37: 1106-1116.

Giovannucci E, Liu Y, Platz EA, Stampfer MJ, Willett WC 2007. Risk factors for prostate cancer incidence and progression in the health professionals follow-up study. Int $J$ Cancer 121: 1571-1578.

Golman K, Petersson JS. 2006. Metabolic imaging and other applications of hyperpolarized ${ }^{13} \mathrm{C}^{1}$. Acad Radiol 13: 932 942. 
Goodacre R, Vaidyanathan S, Dunn WB, Harrigan GG, Kell DB. 2004. Metabolomics by numbers: Acquiring and understanding global metabolite data. Trends Biotechnol 22: 245-252.

Gurel B, Iwata T, Koh CM, Jenkins RB, Lan F, Van Dang C, Hicks JL, Morgan J, Cornish TC, Sutcliffe S, et al. 2008 Nuclear MYC protein overexpression is an early alteration in human prostate carcinogenesis. Mod Pathol 21: 1156-1167.

Hricak H. 2005. MR imaging and MR spectroscopic imaging in the pre-treatment evaluation of prostate cancer. $\mathrm{Br} \mathrm{J}$ Radiol 78: S103-S111.

Hsieh AL, Walton ZE, Altman BJ, Stine ZE, Dang CV. 2015 MYC and metabolism on the path to cancer. Semin Cell Dev Biol 43: 11-21.

Iurlaro R, Leon-Annicchiarico CL, Munoz-Pinedo C. 2014. Regulation of cancer metabolism by oncogenes and tumor suppressors. Methods Enzymol 542: 59-80.

Jadvar H. 2009. Molecular imaging of prostate cancer with ${ }^{18}$ F-fluorodeoxyglucose PET. Nat Rev Urol 6: 317-323.

Jadvar H. 2011. Prostate cancer: PET with ${ }^{18} \mathrm{~F}-\mathrm{FDG},{ }^{18} \mathrm{~F}-$ or ${ }^{11} \mathrm{C}$-acetate, and ${ }^{18} \mathrm{~F}$ - or ${ }^{11} \mathrm{C}$-choline. J Nucl Med 52: $81-89$.

Jadvar H. 2012. Molecular imaging of prostate cancer: PET radiotracers. AJR Am J Roentgenol 199: 278-291.

Jariwala U, Prescott J, Jia L, Barski A, Pregizer S, Cogan JP, Arasheben A, Tilley WD, Scher HI, Gerald WL, et al. 2007. Identification of novel androgen receptor target genes in prostate cancer. Mol Cancer 6: 39 .

Javali TD, Dwivedi DK, Kumar R, Jagannathan NR, Thulkar S, Dinda AK. 2014. Magnetic resonance spectroscopy imaging-directed transrectal ultrasound biopsy increases prostate cancer detection in men with prostate-specific antigen between $4-10 \mathrm{ng} / \mathrm{mL}$ and normal digital rectal examination. Int J Urol 21: 257-262.

Jenkins RB, Qian J, Lieber MM, Bostwick DG. 1997. Detection of c-myc oncogene amplification and chromosomal anomalies in metastatic prostatic carcinoma by fluorescence in situ hybridization. Cancer Res 57: 524-531.

Jones SF, Infante JR. 2015. Molecular pathways: Fatty acid synthase. Clin Cancer Res 21: 5434-5438.

Kaushik AK, Shojaie A, Panzitt K, Sonavane R, Venghatakrishnan H, Manikkam M, Zaslavsky A, Putluri V, Vasu VT, Zhang Y, et al. 2016. Inhibition of the hexosamine biosynthetic pathway promotes castration-resistant prostate cancer. Nat Commun 7: 11612.

Kelly RS, Vander Heiden MG, Giovannucci E, Mucci LA. 2016. Metabolomic biomarkers of prostate cancer: Prediction, diagnosis, progression, prognosis, and recurrence. Cancer Epidemiol Biomarkers Prev 25: 887-906.

Khan AS, Frigo DE. 2017. A spatiotemporal hypothesis for the regulation, role, and targeting of AMPK in prostate cancer. Nat Rev Urol 14: 164-180.

Khan AP, Rajendiran TM, Ateeq B, Asangani IA, Athanikar JN, Yocum AK, Mehra R, Siddiqui J, Palapattu G, Wei JT, et al. 2013. The role of sarcosine metabolism in prostate cancer progression. Neoplasia 15: 491-501.

Kimmelman AC. 2015. Metabolic dependencies in RASdriven cancers. Clin Cancer Res 21: 1828-1834.
Kinnaird A, Zhao S, Wellen KE, Michelakis ED. 2016. Metabolic control of epigenetics in cancer. Nat Rev Cancer 16: 694-707.

Kobayashi N, Barnard RJ, Said J, Hong-Gonzalez J, Corman DM, Ku M, Doan NB, Gui D, Elashoff D, Cohen P, et al. 2008. Effect of low-fat diet on development of prostate cancer and Akt phosphorylation in the Hi-Myc transgenic mouse model. Cancer Res 68: 3066-3073.

Kochuparambil ST, Al-Husein B, Goc A, Soliman S, Somanath PR. 2011. Anticancer efficacy of simvastatin on prostate cancer cells and tumor xenografts is associated with inhibition of Akt and reduced prostate-specific antigen expression. J Pharmacol Exp Ther 336: 496-505.

Koh CM, Bieberich CJ, Dang CV, Nelson WG, Yegnasubramanian S, De Marzo AM. 2010. MYC and prostate cancer. Genes Cancer 1: 617-628.

Kok DE, van Roermund JG, Aben KK, den Heijer M, Swinkels DW, Kampman E, Kiemeney LA. 2011. Blood lipid levels and prostate cancer risk; a cohort study. Prostate Cancer Prostatic Dis 14: 340-345.

Kotzerke J, Gschwend JE, Neumaier B. 2002. PET for prostate cancer imaging: Still a quandary or the ultimate solution? J Nucl Med 43: 200-202.

Krause BJ, Souvatzoglou M, Herrmann K, Weber AW, Schuster T, Buck AK, Nawroth R, Weirich G, Treiber U, Wester HJ, et al. 2010. $\left[{ }^{11} \mathrm{C}\right]$ Choline as pharmacodynamic marker for therapy response assessment in a prostate cancer xenograft model. Eur J Nucl Med Mol Imaging 37: 1861-1868.

Kuemmerle NB, Rysman E, Lombardo PS, Flanagan AJ, Lipe BC, Wells WA, Pettus JR, Froehlich HM, Memoli VA, Morganelli PM, et al. 2011. Lipoprotein lipase links dietary fat to solid tumor cell proliferation. Mol Cancer Ther 10: $427-436$.

Kuo TC, Tian TF, Tseng YJ. 2013. 3Omics: A web-based systems biology tool for analysis, integration and visualization of human transcriptomic, proteomic and metabolomic data. BMC Syst Biol 7: 64.

Kurhanewicz J, Vigneron DB. 2008. Advances in MR spectroscopy of the prostate. Magn Reson Imaging Clin N Am 16: $697-710$, ix-x.

Kurhanewicz J, Vigneron DB, Hricak H, Narayan P, Carroll P, Nelson SJ. 1996. Three-dimensional H-1 MR spectroscopic imaging of the in situ human prostate with high $\left(0.24-0.7 \mathrm{~cm}^{3}\right)$ spatial resolution. Radiology 198: 795805.

Kurhanewicz J, Vigneron D, Carroll P, Coakley F. 2008. Multiparametric magnetic resonance imaging in prostate cancer: Present and future. Curr Opin Urol 18: 71-77.

Kurhanewicz J, Vigneron DB, Brindle K, Chekmenev EY, Comment A, Cunningham CH, Deberardinis RJ, Green GG, Leach MO, Rajan SS, et al. 2011. Analysis of cancer metabolism by imaging hyperpolarized nuclei: Prospects for translation to clinical research. Neoplasia 13: 81-97.

Labbé DP, Zadra G, Ebot EM, Mucci LA, Kantoff PW, Loda M, Brown M. 2015. Role of diet in prostate cancer: The epigenetic link. Oncogene 34: 4683-4691.

Laurent V, Guerard A, Mazerolles C, Le Gonidec S, Toulet A, Nieto L, Zaidi F, Majed B, Garandeau D, Socrier Y, et al. 2016. Periprostatic adipocytes act as a driving force for prostate cancer progression in obesity. Nat Commun 7: 10230. 
Li R, Younes M, Frolov A, Wheeler TM, Scardino P, Ohori M, Ayala G. 2003. Expression of neutral amino acid transporter ASCT2 in human prostate. Anticancer Res 23: 3413-3418.

Li W, Cohen A, Sun Y, Squires J, Braas D, Graeber TG, Du L, Li G, Li Z, Xu X, et al. 2016. The role of CD44 in glucose metabolism in prostatic small cell neuroendocrine carcinoma. Mol Cancer Res 14: 344-353.

Liu W, Le A, Hancock C, Lane AN, Dang CV, Fan TW, Phang JM. 2012. Reprogramming of proline and glutamine metabolism contributes to the proliferative and metabolic responses regulated by oncogenic transcription factor c-MYC. Proc Natl Acad Sci 109: 8983-8988.

Liu J, Ramakrishnan SK, Khuder SS, Kaw MK, Muturi HT, Lester SG, Lee SJ, Fedorova LV, Kim AJ, Mohamed IE, et al. 2015a. High-calorie diet exacerbates prostate neoplasia in mice with haploinsufficiency of Pten tumor suppressor gene. Mol Metab 4: 186-198.

Liu W, Hancock CN, Fischer JW, Harman M, Phang JM. 2015b. Proline biosynthesis augments tumor cell growth and aerobic glycolysis: Involvement of pyridine nucleotides. Sci Rep 5: 17206.

Louie SM, Roberts LS, Mulvihill MM, Luo K, Nomura DK. 2013. Cancer cells incorporate and remodel exogenous palmitate into structural and oncogenic signaling lipids. Biochim Biophys Acta 1831: 1566-1572.

Luo J, Zha S, Gage WR, Dunn TA, Hicks JL, Bennett CJ, Ewing CM, Platz EA, Ferdinandusse S, Wanders RJ, et al. 2002. $\alpha$-Methylacyl-CoA racemase: A new molecular marker for prostate cancer. Cancer Res 62: 2220-2226.

Lustman A, Nakar S, Cohen AD, Vinker S. 2014. Statin use and incident prostate cancer risk: Does the statin brand matter? A population-based cohort study. Prostate Cancer Prostatic Dis 17: 6-9.

Lynch TP, Ferrer CM, Jackson SR, Shahriari KS, Vosseller K, Reginato MJ. 2012. Critical role of $O$-linked $\beta$ - $N$-acetylglucosamine transferase in prostate cancer invasion, angiogenesis, and metastasis. J Biol Chem 287: 1107011081.

Ma Z, Vosseller K. 2014. Cancer metabolism and elevated $\mathrm{O}$-GlcNAc in oncogenic signaling. J Biol Chem 289: 34457-34465.

Magura L, Blanchard R, Hope B, Beal JR, Schwartz GG, Sahmoun AE. 2008. Hypercholesterolemia and prostate cancer: A hospital-based case-control study. Cancer Causes Control 19: 1259-1266.

Matthies A, Ezziddin S, Ulrich EM, Palmedo H, Biersack HJ, Bender H, Guhlke S. 2004. Imaging of prostate cancer metastases with ${ }^{18} \mathrm{~F}$-fluoroacetate using PET/CT. Eur J Nucl Med Mol Imaging 31: 797.

McDunn JE, Li Z, Adam KP, Neri BP, Wolfert RL, Milburn MV, Lotan Y, Wheeler TM. 2013. Metabolomic signatures of aggressive prostate cancer. Prostate 73: 15471560.

Mentch SJ, Locasale JW. 2016. One-carbon metabolism and epigenetics: Understanding the specificity. Ann NY Acad Sci 1363: 91-98.

Migita T, Ruiz S, Fornari A, Fiorentino M, Priolo C, Zadra G, Inazuka F, Grisanzio C, Palescandolo E, Shin E, et al. 2009. Fatty acid synthase: A metabolic enzyme and candidate oncogene in prostate cancer. J Natl Cancer Inst 101: 519-532.
Miyazawa Y, Sekine Y, Kato H, Furuya Y, Koike H, Suzuki K. 2017. Simvastatin up-regulates annexin A10 that can inhibit the proliferation, migration, and invasion in androgen-independent human prostate cancer cells. Prostate 77: 337-349.

Montgomery RB, Mostaghel EA, Vessella R, Hess DL, Kalhorn TF, Higano CS, True LD, Nelson PS. 2008. Maintenance of intratumoral androgens in metastatic prostate cancer: A mechanism for castration-resistant tumor growth. Cancer Res 68: 4447-4454.

Mullen AR, Wheaton WW, Jin ES, Chen PH, Sullivan LB, Cheng T, Yang Y, Linehan WM, Chandel NS, DeBerardinis RJ. 2012. Reductive carboxylation supports growth in tumour cells with defective mitochondria. Nature 481: 385-388.

Nagarajan A, Malvi P, Wajapeyee N. 2016. Oncogene-directed alterations in cancer cell metabolism. Trends Cancer $\mathbf{2}$ : 365-377.

Nelson SJ, Kurhanewicz J, Vigneron DB, Larson PE, Harzstark AL, Ferrone M, van Criekinge M, Chang JW, Bok R, Park I, et al. 2013. Metabolic imaging of patients with prostate cancer using hyperpolarized $\left[1-{ }^{13} \mathrm{C}\right]$ pyruvate. Sci Transl Med 5: 198ra108.

Nicholson A, Mahon J, Boland A, Beale S, Dwan K, Fleeman N, Hockenhull J, Dundar Y. 2015. The clinical effectiveness and cost-effectiveness of the PROGENSA(R) prostate cancer antigen 3 assay and the Prostate Health Index in the diagnosis of prostate cancer: A systematic review and economic evaluation. Health Technol Assess 19: ixxxi, 1-191.

Nicklin P, Bergman P, Zhang B, Triantafellow E, Wang $\mathrm{H}$, Nyfeler B, Yang H, Hild M, Kung C, Wilson C, et al. 2009. Bidirectional transport of amino acids regulates mTOR and autophagy. Cell 136: 521-534.

Nomura DK, Long JZ, Niessen S, Hoover HS, Ng SW, Cravatt BF. 2010. Monoacylglycerol lipase regulates a fatty acid network that promotes cancer pathogenesis. Cell 140: 49-61.

Nomura DK, Lombardi DP, Chang JW, Niessen S, Ward AM, Long JZ, Hoover HH, Cravatt BF. 2011. Monoacylglycerol lipase exerts dual control over endocannabinoid and fatty acid pathways to support prostate cancer. Chem Biol 18: 846-856.

Nuñez R, Macapinlac HA, Yeung HW, Akhurst T, Cai S, Osman I, Gonen M, Riedel E, Scher HI, Larson SM 2002. Combined ${ }^{18} \mathrm{~F}-\mathrm{FDG}$ and ${ }^{11} \mathrm{C}$-methionine PET scans in patients with newly progressive metastatic prostate cancer. J Nucl Med 43: 46-55.

Oka S, Hattori R, Kurosaki F, Toyama M, Williams LA, Yu W, Votaw JR, Yoshida Y, Goodman MM, Ito O. 2007. A preliminary study of anti-1-amino- $3-{ }^{18} \mathrm{~F}$-fluorocyclobutyl-1-carboxylic acid for the detection of prostate cancer. $J$ Nucl Med 48: 46-55.

Oyama N, Akino H, Suzuki Y, Kanamaru H, Ishida H, Tanase K, Sadato N, Yonekura Y, Okada K. 2001. FDG PET for evaluating the change of glucose metabolism in prostate cancer after androgen ablation. Nucl Med Commun 22: 963-969.

Oyama N, Miller TR, Dehdashti F, Siegel BA, Fischer KC, Michalski JM, Kibel AS, Andriole GL, Picus J, Welch MJ. 2003. ${ }^{11} \mathrm{C}$-acetate PET imaging of prostate cancer: Detec- 
tion of recurrent disease at PSA relapse. J Nucl Med 44: 549-555.

Pelton K, Freeman MR, Solomon KR. 2012. Cholesterol and prostate cancer. Curr Opin Pharmacol 12: 751-759.

Penney KL, Sinnott JA, Fall K, Pawitan Y, Hoshida Y, Kraft P, Stark JR, Fiorentino M, Perner S, Finn S, et al. 2011. mRNA expression signature of Gleason grade predicts lethal prostate cancer. J Clin Oncol 29: 2391-2396.

Pertega-Gomes N, Vizcaino JR, Gouveia C, Jeronimo C, Henrique RM, Lopes C, Baltazar F. 2013. Monocarboxylate transporter 2 (MCT2) as putative biomarker in prostate cancer. Prostate 73: 763-769.

Picchio M, Spinapolice EG, Fallanca F, Crivellaro C, Giovacchini G, Gianolli L, Messa C. 2012. $\left[{ }^{11} \mathrm{C}\right]$ Choline PET/CT detection of bone metastases in patients with PSA progression after primary treatment for prostate cancer: Comparison with bone scintigraphy. Eur J Nucl Med Mol Imaging 39: 13-26.

Pickett B, Ten Haken RK, Kurhanewicz J, Qayyum A, Shinohara K, Fein B, Roach M III. 2004. Time to metabolic atrophy after permanent prostate seed implantation based on magnetic resonance spectroscopic imaging. Int $J$ Radiat Oncol Biol Phys 59: 665-673.

Platz EA, Leitzmann MF, Visvanathan K, Rimm EB, Stampfer MJ, Willett WC, Giovannucci E. 2006. Statin drugs and risk of advanced prostate cancer. J Natl Cancer Inst 98: 1819-1825.

Prando A, Kurhanewicz J, Borges AP, Oliveira EM Jr, Figueiredo E. 2005. Prostatic biopsy directed with endorectal MR spectroscopic imaging findings in patients with elevated prostate specific antigen levels and prior negative biopsy findings: Early experience. Radiology 236: $903-$ 910.

Priolo C, Loda M. 2015. Untargeted metabolomics for profiling oncogene-specific metabolic signatures of prostate cancer. Mol Cell Oncol 2: e1001197.

Priolo C, Pyne S, Rose J, Regan ER, Zadra G, Photopoulos C, Cacciatore S, Schultz D, Scaglia N, McDunn J, et al. 2014 AKT1 and MYC induce distinctive metabolic fingerprints in human prostate cancer. Cancer Res 74: 7198-7204.

Putluri N, Shojaie A, Vasu VT, Nalluri S, Vareed SK, Putluri V, Vivekanandan-Giri A, Byun J, Pennathur S, Sana TR, et al. 2011. Metabolomic profiling reveals a role for androgen in activating amino acid metabolism and methylation in prostate cancer cells. PloS ONE 6: e21417.

Richter JA, Rodriguez M, Rioja J, Penuelas I, Marti-Climent J, Garrastachu P, Quincoces G, Zudaire J, Garcia-Velloso MJ. 2010. Dual tracer ${ }^{11} \mathrm{C}$-choline and FDG-PET in the diagnosis of biochemical prostate cancer relapse after radical treatment. Mol Imaging Biol 12: 210-217.

Robinson D, Van Allen EM, Wu YM, Schultz N, Lonigro RJ, Mosquera JM, Montgomery B, Taplin ME, Pritchard CC, Attard G, et al. 2015. Integrative clinical genomics of advanced prostate cancer. Cell 161: 1215-1228.

Röhrig F, Schulze A. 2016. The multifaceted roles of fatty acid synthesis in cancer. Nat Rev Cancer 16: 732-749.

Rossi S, Graner E, Febbo P, Weinstein L, Bhattacharya N, Onody T, Bubley G, Balk S, Loda M. 2003. Fatty acid synthase expression defines distinct molecular signatures in prostate cancer. Mol Cancer Res 1: 707-715.
Rubin MA, Zhou M, Dhanasekaran SM, Varambally S, Barrette TR, Sanda MG, Pienta KJ, Ghosh D, Chinnaiyan AM. 2002. $\alpha$-Methylacyl coenzyme A racemase as a tissue biomarker for prostate cancer. JAMA 287: 1662-1670.

Salminen E, Hogg A, Binns D, Frydenberg M, Hicks R. 2002. Investigations with FDG-PET scanning in prostate cancer show limited value for clinical practice. Acta Oncol 41: 425-429.

Sancak Y, Bar-Peled L, Zoncu R, Markhard AL, Nada S, Sabatini DM. 2010. Ragulator-Rag complex targets mTORC1 to the lysosomal surface and is necessary for its activation by amino acids. Cell 141: 290-303.

Sandblom G, Sorensen J, Lundin N, Haggman M, Malmstrom PU. 2006. Positron emission tomography with C-11-acetate for tumor detection and localization in patients with prostate-specific antigen relapse after radical prostatectomy. Urology 67: 996-1000.

Schlaepfer IR, Rider L, Rodrigues LU, Gijon MA, Pac CT, Romero L, Cimic A, Sirintrapun SJ, Glode LM, Eckel RH, et al. 2014. Lipid catabolism via CPT1 as a therapeutic target for prostate cancer. Mol Cancer Ther 13: 23612371.

Schug ZT, Peck B, Jones DT, Zhang Q, Grosskurth S, Alam IS, Goodwin LM, Smethurst E, Mason S, Blyth K, et al. 2015. Acetyl-CoA synthetase 2 promotes acetate utilization and maintains cancer cell growth under metabolic stress. Cancer Cell 27: 57-71.

Schumacher MC, Radecka E, Hellstrom M, Jacobsson H, Sundin A. 2015. $\left[{ }^{11} \mathrm{C}\right]$ Acetate positron emission tomography-computed tomography imaging of prostate cancer lymph-node metastases correlated with histopathological findings after extended lymphadenectomy. Scand J Urol 49: 35-42.

Schuster DM, Savir-Baruch B, Nieh PT, Master VA, Halkar RK, Rossi PJ, Lewis MM, Nye JA, Yu W, Bowman FD, et al. 2011. Detection of recurrent prostate carcinoma with anti1-amino- $3{ }^{18} \mathrm{~F}$-fluorocyclobutane-1-carboxylic acid PET/ $\mathrm{CT}$ and ${ }^{111}$ In-capromab pendetide SPECT/CT. Radiology 259: 852-861.

Singh KK, Desouki MM, Franklin RB, Costello LC. 2006. Mitochondrial aconitase and citrate metabolism in malignant and nonmalignant human prostate tissues. $\mathrm{Mol}$ Cancer 5: 14

Stine ZE, Walton ZE, Altman BJ, Hsieh AL, Dang CV. 2015. MYC, metabolism, and cancer. Cancer Discov 5: 1024 1039.

Swinnen JV, Vanderhoydonc F, Elgamal AA, Eelen M, Vercaeren I, Joniau S, Van Poppel H, Baert L, Goossens K, Heyns W, et al. 2000. Selective activation of the fatty acid synthesis pathway in human prostate cancer. Int $\mathrm{J}$ Cancer 88: $176-179$.

Swinnen JV, Roskams T, Joniau S, Van Poppel H, Oyen R, Baert L, Heyns W, Verhoeven G. 2002. Overexpression of fatty acid synthase is an early and common event in the development of prostate cancer. Int J Cancer 98: 19-22.

Tamura K, Makino A, Hullin-Matsuda F, Kobayashi T, Furihata M, Chung S, Ashida S, Miki T, Fujioka T, Shuin T, et al 2009. Novel lipogenic enzyme ELOVL7 is involved in prostate cancer growth through saturated long-chain fatty acid metabolism. Cancer Res 69: 8133-8140. 
G. Zadra and M. Loda

The Cancer Genome Atlas Research Network. 2015. The molecular taxonomy of primary prostate cancer. Cell 163: $1011-1025$.

Tóth G, Lengyel Z, Balkay L, Salah MA, Trón L, Tóth C 2005. Detection of prostate cancer with ${ }^{11} \mathrm{C}$-methionine positron emission tomography. J Urol 173: 66-69; discussion 69.

Tsouko E, Khan AS, White MA, Han JJ, Shi Y, Merchant FA, Sharpe MA, Xin L, Frigo DE. 2014. Regulation of the pentose phosphate pathway by an androgen receptormTOR-mediated mechanism and its role in prostate cancer cell growth. Oncogenesis 3: e10.

Tuncel M, Souvatzoglou M, Herrmann K, Stollfuss J, Schuster T, Weirich G, Wester HJ, Schwaiger M, Krause BJ. 2008. $\left.{ }^{11} \mathrm{C}\right]$ Choline positron emission tomography/computed tomography for staging and restaging of patients with advanced prostate cancer. Nucl Med Biol 35: 689695.

Ulrich CM, Potter JD. 2007. Folate and cancer-Timing is everything. JAMA 297: 2408-2409.

Umbehr M, Bachmann LM, Held U, Kessler TM, Sulser T, Weishaupt D, Kurhanewicz J, Steurer J. 2009. Combined magnetic resonance imaging and magnetic resonance spectroscopy imaging in the diagnosis of prostate cancer: A systematic review and meta-analysis. Eur Urol 55: 575590.

Vander Heiden MG, Cantley LC, Thompson CB. 2009 Understanding the Warburg effect: The metabolic requirements of cell proliferation. Science 324: 1029-1033.

Venneti S, Dunphy MP, Zhang H, Pitter KL, Zanzonico P, Campos C, Carlin SD, La Rocca G, Lyashchenko S, Ploessl $\mathrm{K}$, et al. 2015. Glutamine-based PET imaging facilitates enhanced metabolic evaluation of gliomas in vivo. Sci Transl Med 7: 274 ra217.

Verma S, Rajesh A, Futterer JJ, Turkbey B, Scheenen TW, Pang Y, Choyke PL, Kurhanewicz J. 2010. Prostate MRI and 3D MR spectroscopy: How we do it. AJR Am J Roentgenol 194: 1414-1426.

Wang Q, Bailey CG, Ng C, Tiffen J, Thoeng A, Minhas V, Lehman ML, Hendy SC, Buchanan G, Nelson CC, et al 2011. Androgen receptor and nutrient signaling pathways coordinate the demand for increased amino acid transport during prostate cancer progression. Cancer Res 71: 7525-7536.

Wang Q, Hardie RA, Hoy AJ, van Geldermalsen M, Gao D, Fazli L, Sadowski MC, Balaban S, Schreuder M, Nagarajah $\mathrm{R}$, et al. 2015. Targeting ASCT2-mediated glutamine up- take blocks prostate cancer growth and tumour development. J Pathol 236: 278-289.

Williams-Ashman HG, Canellakis ZN. 1979. Polyamines in mammalian biology and medicine. Perspect Biol Med 22: 421-453.

Wise DR, Thompson CB. 2010. Glutamine addiction: A new therapeutic target in cancer. Trends Biochem Sci 35: 427433.

Wise HM, Hermida MA, Leslie NR. 2017. Prostate cancer, PI3K, PTEN and prognosis. Clin Sci 131: 197-210.

Wishart DS, Mandal R, Stanislaus A, Ramirez-Gaona M. 2016. Cancer metabolomics and the human metabolome database. Metabolites doi: 10.3390/metabo6010010.

Wullschleger S, Loewith R, Hall MN. 2006. TOR signaling in growth and metabolism. Cell 124: 471-484.

Yegnasubramanian S, Haffner MC, Zhang Y, Gurel B, Cornish TC, Wu Z, Irizarry RA, Morgan J, Hicks J, DeWeese TL, et al. 2008. DNA hypomethylation arises later in prostate cancer progression than $\mathrm{CpG}$ island hypermethylation and contributes to metastatic tumor heterogeneity. Cancer Res 68: 8954-8967.

Yue S, Li J, Lee SY, Lee HJ, Shao T, Song B, Cheng L, Masterson TA, Liu X, Ratliff TL, et al. 2014. Cholesteryl ester accumulation induced by PTEN loss and PI3K/AKT activation underlies human prostate cancer aggressiveness. Cell Metab 19: 393-406.

Zadra G, Photopoulos C, Loda M. 2013. The fat side of prostate cancer. Biochim Biophys Acta 1831: 1518-1532.

Zadra G, Batista JL, Loda M. 2015. Dissecting the dual role of AMPK in cancer: From experimental to human studies. Mol Cancer Res 13: 1059-1072.

Zaidi N, Lupien L, Kuemmerle NB, Kinlaw WB, Swinnen JV, Smans K. 2013. Lipogenesis and lipolysis: The pathways exploited by the cancer cells to acquire fatty acids. Prog Lipid Res 52: 585-589.

Zakian KL, Eberhardt S, Hricak H, Shukla-Dave A, Kleinman S, Muruganandham M, Sircar K, Kattan MW, Reuter VE, Scardino PT, et al. 2003. Transition zone prostate cancer: Metabolic characteristics at ${ }^{1} \mathrm{H}$ MR spectroscopic imaging-Initial results. Radiology 229: 241-247.

Zamboni N, Saghatelian A, Patti GJ. 2015. Defining the metabolome: Size, flux, and regulation. Mol Cell 58: 699-706.

Zoncu R, Bar-Peled L, Efeyan A, Wang S, Sancak Y, Sabatini DM. 2011. mTORC1 senses lysosomal amino acids through an inside-out mechanism that requires the vacuolar $\mathrm{H}^{+}$-ATPase. Science 334: 678-683. 


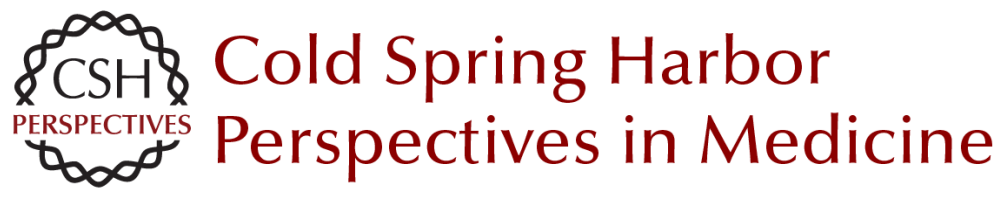

\section{Metabolic Vulnerabilities of Prostate Cancer: Diagnostic and Therapeutic Opportunities}

Giorgia Zadra and Massimo Loda

Cold Spring Harb Perspect Med 2018; doi: 10.1101/cshperspect.a030569 originally published online December 11, 2017

\section{Subject Collection Prostate Cancer}

Anatomic and Molecular Imaging in Prostate

Cancer

Eric T. Miller, Amirali Salmasi and Robert E. Reiter

The Epidemiology of Prostate Cancer

Claire H. Pernar, Ericka M. Ebot, Kathryn M. Wilson, et al.

Prostate Stem Cells and Cancer Stem Cells Jia J. Li and Michael M. Shen

Prostate Cancer Epigenetics: From Basic Mechanisms to Clinical Implications Srinivasan Yegnasubramanian, Angelo M. De Marzo and William G. Nelson

The Genomics of Prostate Cancer: A Historic Perspective Mark A. Rubin and Francesca Demichelis

Neuroendocrine Differentiation in Prostate Cancer: Emerging Biology, Models, and Therapies Loredana Puca, Panagiotis J. Vlachostergios and Himisha Beltran

DNA Damage Response in Prostate Cancer Matthew J. Schiewer and Karen E. Knudsen

Transcriptional Regulation in Prostate Cancer David P. Labbé and Myles Brown
New Opportunities for Targeting the Androgen

Receptor in Prostate Cancer Margaret M. Centenera, Luke A. Selth, Esmaeil Ebrahimie, et al.

Prostate Cancer Research at the Crossroads Michael M. Shen and Mark A. Rubin

Immunotherapy for Prostate Cancer Nicholas J. Venturini and Charles G. Drake

Molecular Pathology of High-Grade Prostatic Intraepithelial Neoplasia: Challenges and Opportunities Levent Trabzonlu, Ibrahim Kulac, Qizhi Zheng, et al.

Metastases in Prostate Cancer Federico La Manna, Sofia Karkampouna, Eugenio Zoni, et al.

Genetically Engineered Mouse Models of Prostate Cancer in the Postgenomic Era Juan M. Arriaga and Cory Abate-Shen

Molecular Biomarkers in the Clinical Management of Prostate Cancer Aaron M. Udager and Scott A. Tomlins

Metabolic Vulnerabilities of Prostate Cancer: Diagnostic and Therapeutic Opportunities Giorgia Zadra and Massimo Loda

For additional articles in this collection, see http://perspectivesinmedicine.cshlp.org/cgi/collection/ 